\title{
Associate Teachers' Learning Networks: A Figurational Analysis of Initial Teacher Education
}

\author{
Luke Jones, Steven Tones and Gethin Foulkes \\ Faculty of Education and Children's Services, University of Chester, Parkgate Road, \\ Chester, UK
}

\begin{abstract}
Purpose - The aim of this paper is to use the lens of figurational sociology to analyse the learning networks of physical education (PE) associate teachers (ATs) in England. More specifically, it aims to develop a more adequate understanding of who is involved in the learning networks and how they influence ATs during their one-year postgraduate initial teacher education (ITE) programme.
\end{abstract}

Design/methodology/approach - A total of 35 ATs within a university ITE partnership took part in the study during the final phase of their postgraduate programme. Questionnaires and semi-structured interviews were used to examine the nature and impact of the interdependent relationships that they had developed with other individuals and groups. A process of content analysis was used to identify and analyse patterns in the data.

Findings - Mentors have the most influence over ATs. They support the inclusion of the ATs within the PE department, but elements of the mentors' role are contradictory and can unintentionally hinder the ATs' teaching. Mentors, teachers and tutors also share a common social habitus that ensures a degree of conformity within the PE community. New experiences tend to reinforce ATs' existing beliefs about the nature and practice of teaching PE.

Practical implications - These findings have implications for providers of ITE in deciding who is involved in mentor training and how it is approached. If ATs are to be introduced to more innovative teaching approaches that promote change, then tutors need to collaborate with mentors and teachers to develop awareness of their often-unplanned influence.

Originality/value - Applying the distinctive, and more generally sociological, concepts that make up the figurational perspective helped to develop a more adequate understanding of the ATs' learning networks. It provided an insight into the changing relationships that ATs have with their mentors and other individuals who work within the school and university context.

Key words - learning networks, physical education, mentor, associate teacher, initial teacher education

Paper type - Case study 


\section{Introduction}

This paper examines how associate teachers (ATs) (also referred to as trainee or pre-service teachers) are influenced by those they work alongside during their one-year postgraduate initial teacher education (ITE) programme. More specifically, it explores the ways in which Norbert Elias's (1978) figurational sociology can offer a useful lens through which to understand ATs' experiences as they learn to teach physical education (PE). This analysis is inevitably focused on the AT's relationship with their designated subject mentor, a more experienced school-based colleague who plays a central role in their teacher education (Jones et al., 2018, 2019; Lofthouse, 2017), but also considers the influence of other individuals in their networks who provide different levels of support, encouragement and guidance.

The paper builds upon previous work that examined the mentoring of PE ATs, and more specifically the value of the dialogic feedback that occurs in schools and the nature of the learning conversations that take place between the mentor and the AT. Our initial research (see Jones et al., 2018) revealed that both mentors and ATs began to adopt and value more informal dialogic (Bokeno and Gantt, 2000) approaches to feedback during the final phase of a one-year ITE programme. Initially, mentors tend to rely on monological mentoring approaches (Bokeno and Gantt, 2000) where feedback is provided through formal lesson observations, with ATs being assessed against predetermined criteria. This hierarchical approach can encourage ATs to reproduce existing and dominant models of teaching and learning (Nahmad-Williams and Taylor, 2015; Wang and Odell, 2002) and is characteristic of what Hobson (2016) called 'judgementoring', where one-way conversations about competency allow less room for reflection, innovation and discovery. In contrast, moving to a dialogic approach is said to reframe the relationship of the mentor and AT and positions them as a collaborative and reciprocal partnership (Cassidy et al., 2004; Lofthouse and Wright, 2012; Wang and Odell, 2002). When adopting what Bokeno and Gantt (2000) termed a dialogic model, mentors are not expected to simply deliver pedagogical knowledge to ATs but to promote inquiry and reflection and to use collaborative learning conversations to develop thinking and shared understanding (Nahmad-Williams and Taylor, 2015).

A subsequent paper on mentoring examined the nature of the learning conversations that take place between the PE subject mentors and their ATs (Jones et al., 2019). Dialogic feedback was again found to be effective as this approach engaged the AT in a two-way conversation 
that promoted a greater level of independent thinking (Bokeno and Gantt, 2000). In addition, more informal two-way learning conversations that occurred away from lessons as part of everyday discussions were valued by ATs. They were thought to nurture a reciprocal and collaborative relationship (Gordon, 2017) that allowed the AT access to their mentor's individual resources and to their wider learning network. Moreover, these learning conversations provided opportunities for the AT to share their emerging ideas and experience their constructive impact on the knowledge and teaching of their mentor. Finally, the impact of informal everyday conversations was not limited to the interactions with the mentor, as other teachers played a role in the development of the AT. Successful mentoring was not realised through an isolated weekly lesson observation of the ATs' teaching. It was an immersive process where the AT, the mentor and others in the school network faced the ongoing challenge of exploring aspects of pedagogy and developing a relationship conducive to shared learning.

Our findings drew attention to the nature of the conversations that ATs share with mentors, and others in the school network, and to the paucity of research in this area, particularly within the context of teacher education and even more so within PE teacher education. The present paper aims to draw on figurational sociology to develop a more detailed understanding of the ATs' learning networks. More specifically, it begins by explaining some of the distinctive, and more generally sociological, concepts that make up the figurational perspective and how they can be applied in the analysis of ATs and their changing relationships with mentors and other individuals within a school context. To this end, the next section introduces a number of interrelated sociological concepts that together inform the figurational perspective adopted in the paper. These key concepts include networks of interdependent relationships (or figurations), habitus, power and unintended outcomes.

\section{Figurational Sociology}

Elias (1978) used the central concept of the 'figuration' to explain the complex nature of social relationships. Figurations are the multi-layered networks of interdependent relationships that are formed between individuals and groups in society. Elias believed that while people do not have individual control over figurations, they are inescapably part of them. This in turn influences social behaviour as people do not act in isolation but are constrained in their thoughts and behaviours by others in their networks (Green, 2002). Thus, human behaviour is thought 
to be more adequately understood when it is examined in the context of the interdependent relationships that individuals and groups have with each other (Dunning and Hughes, 2013).

The social interactions that occur within figurations are thought to influence behaviour and result in the formation of individual habitus. For Elias, habitus refers to the deeply engrained 'second nature' that is established in people as an aspect of social interdependencies. This conception is different from the understanding of habitus that has arguably come to greater prominence, despite emerging later, through the work of Bourdieu (Dunning, 2002). While there are clear similarities between the two, Bourdieu's use of the term characteristically includes greater reference to bodily habitus, while Elias emphasises a conception that is centred on personality structure and habitual behaviour (Dunning, 2002; Van Krieken, 1998). For Elias (1994), habitus relates to an 'automatic self-restraint, a habit that, within certain limits, also functions when a person is alone' (p.137).

Habitus is socially constructed and acquired through everyday experiences of our relationships with others (Fletcher, 2013; Van Krieken, 1998). The development of a person's habitus occurs within figurations and is linked with the process of socialisation, as individuals learn the norms, values and behaviours that are associated with their social group (Fletcher, 2013). Elias believed that this process occurs over a lifetime and is influenced by our changing social relationships within increasingly complex figurations; but he also maintained that the formative years are the most important in establishing what becomes a deep-rooted personality structure (Green, 2003). The impact of ATs' early experiences as pupils may, for example, be useful in understanding their engrained preference for one pedagogical approach over another, and also help explain the comparatively limited influence of relatively short interventions such as continuing professional development.

The development of a person's habitus was thought by Elias (1988) to occur over a lifetime but to also be founded on the longer term process of the development of human relationships within society (Alfrey and Gard, 2019). The 'understanding that people attribute to different experiences and phenomena, is shaped by the standard way that these forms are thought about within society' (Mennell, 1998, p. 161). In this regard, we are influenced by previous generations, as the norms and values that we internalise have been socially constructed and passed on by earlier human relationships (Murphy et al., 2000). Thus, the personality structure of human beings is rooted in the relationships they form within figurations but is also based on 
a longer term process of social development and change. Within ITE, for example, the values attributed by ATs to the teaching of team games will have been created and passed on by previous generations of teachers. In this regard, the behaviour of ATs is an expression of their habitus, which has been influenced by their involvement in figurations (such as their own experience of PE as pupils) and by the standard way in which the norms and values associated with education have been passed on by previous generations.

The networks of social relationships that form in society are also understood by figurational sociologists as being complex and fluid, in that the number of individuals and groups involved will vary and change over time, as will the nature and strength of the bonds that bind them together (Van Krieken, 1998). Elias (1978) believed that within figurations, some individuals inevitably have greater proportions of the resources that are needed by others, and that this leads to the power relationships that exist within social groups. The power that comes from the control of resources is not absolute, however, as when two or more people are bonded together, the relationship that exists between them is fostered by their mutual dependency on the other(s) to provide a resource. As such, while power is an inevitable characteristic of human relationships, it is never absolute; there is always reliance on others. 'Power is always a question of relative balances, never of absolute possession or absolute deprivation, for no one is ever absolutely powerful or absolutely powerless' (Murphy et al., 2000, p. 93). The relative balance of power is seen in schools, for example, where the hierarchical nature of the organisation provides a head of department with greater control over the allocation of resources and thus the power to make decisions. In comparison, ATs have relatively little power in the school figuration but are not powerless insofar as they are, to some extent, relied upon for their contribution to the provision of PE.

Power is also seen to be a dynamic aspect of relationships (Elias, 1978). The power ratio between a head of department and an AT might change, for example, if the head of department becomes more dependent on that AT than hitherto. If the AT develops expertise in an area that the head of department values, then the power relationship between them would be expected to change. In this regard, Elias used the term 'power balance' to convey his conception of power as being a fluid entity rather than something that is set in a permanent state. The balance of power between individuals or groups may change direction in given circumstances, for as Murphy et al. (2000) noted, 'Power tends to shift and change over time in connection with constantly emerging economic, political, and emotional dimensions of social life' (p.93). 
ATs work in complex educational figurations with an increasingly wide range of individuals (such as mentors, university tutors, heads of department, secondary PE teachers, other ATs, sports coaches and other teachers) and organisations (such as different placement schools, the university, policy makers and governing bodies of sport) (Brondyk and Searby, 2013). The restructuring of human relations in this way was thought by Elias to lead to greater unpredictability. He maintained that where chains of interdependency are lengthened within larger and more complex figurations, the power differentials between individuals and groups are reduced (Green, 2000). Where power becomes more equal in larger groups of people, the more likely it is for the outcomes to vary and for individuals to have less control. 'The very complexity and dynamic character of the interweaving of the actions of large numbers of people continuously give rise to outcomes that no one has chosen, and no one has designed' (Murphy et al., 2000, p. 92). As such, Elias believed that human interaction within figurations has both intended consequences and also unplanned outcomes that are not anticipated or controlled. He thought that societies are composed of individuals and groups who are bonded together in unplanned networks of interdependence, and although human beings engage in intentional actions within these figurations, the outcome is most often unplanned. As such, Elias emphasised an understanding of human action as a 'blind' social process that results in intended and unintended consequences, as he wanted to counter any simplistic interpretation of the relationship between human action and its outcomes (Van Krieken, 1998).

Finally, as unintended outcomes are an inevitable feature of complex and dynamic figurations, characterised by fluctuating balances of power, figurational sociologists believe that human societies can only be understood as consisting of long-term processes of development and change (Van Krieken, 1998). Elias (1987a) spoke in this regard of the 'retreat of sociologists into the present' (p. 223) while his approach was grounded in a longer term historical basis. His argument was that sociologists cannot logically avoid concerning themselves with longterm social processes in order to understand present-day human action, as the norms and values that shape behaviour have been socially constructed by previous generations (Dunning and Hughes, 2013). In this regard, this study refers to the longer term development of PE to provide a context for, and better understanding of, the contemporary nature of the subject.

The underlying idea in Elias's work is that we only exist in and through our relationships with others, and that in order to understand social behaviour it is necessary for its study to be within 
the context of these figurations. The outcome of human action is, he maintained, often unplanned and unintended as it occurs within complex networks where power relationships shift and develop over time (Elias, 1978; Dunning and Hughes, 2013). Examining human actions in relation to key sociological concepts, such as networks of interdependent relationships (or figurations), habitus, power and unintended outcomes, is thought to allow for a more adequate understanding of social behaviour. By analysing ATs in relation to the interrelated sociological concepts that together inform the figurational perspective, it is hoped to develop a more adequate understanding of ITE and the social relationships that influence the professional development of ATs.

\section{Methodology}

\section{Involvement and detachment}

Elias (1987) maintained that it is necessary to retain a detachment or separation from oneself in conducing social research. Elias noted that as society is formed by oneself and other people together, sociologists inevitably study other interdependent human beings and are part of their scientific study. Thus, the interdependent nature of figurations means that social scientists cannot avoid a measure of involvement in their own research and theorising. This proximity can lead to insights that may otherwise have been overlooked, but it can also be a barrier to research as social researchers can be more concerned with sustaining and justifying their own ideological beliefs than in developing a more adequate understanding of social life (Murphy et al., 2000). Thus, Elias (1987) argued that social scientists should go beyond an emotionally conceived view of the human world and take a 'detour via detachment' (p. 6) to increase understanding during the research process. That is, social scientists should aim to distance themselves (as much as it is possible to do so) from their own values, while also recognising that involvement is inevitable in the research of social phenomena.

Elias's model of involvement and detachment was interpreted by Rojek (1992) as 'a methodology of self-consciously distancing oneself from the object of study' (p. 17). This interpretation was rejected by Bloyce (2004) who argued that figurationalists actually strive for a more balanced position that combines involvement and detachment. Elias maintained that all social scientists are influenced by their involvement in the subject area of their research, but this involvement can lead to a level of understanding that would otherwise be compromised by simply distancing oneself from the object of study. Taking a detour via detachment, it is argued, 
enables a researcher to recognise and reduce emotional influences, and in so doing achieve a balance between involvement and detachment that combines the benefits of both in developing a more adequate understanding of the social world. By taking a detour via detachment, the researcher is sufficiently involved to understand the context and gain insights into the field of study, while remaining relatively detached so that they can identify and minimise (but not entirely avoid) emotional influences.

In the context of this study, for example, all of the research team worked in ITE, but to limit the possibility of coercion and bias, recruitment and data generation were undertaken by members of the team who were not previously known to the ATs. Similarly, the data were analysed independently, by all three researchers, before comparing findings. This was done to minimise ideological leanings and strike an appropriate balance between involvement and detachment. In this regard, the concept of involvement and detachment is relevant to the methodology and methods, as well as to the study itself.

\section{Research design}

The longitudinal research project used questionnaires and interviews with three consecutive cohorts of PE ATs. All ATs were completing a yearlong postgraduate qualification in secondary education, with 120 days of the 180-day programme being based in schools. A total of 35 ATs took part in the study during the final phase of their postgraduate programme. Of the three cohorts, 18 were female and 17 were male, while the average age of all participants was 23. A purposive sampling method was used in the selection of participants (Roberts, 2009). All ATs who were learning to teach PE at the authors' institution were invited to participate in the study as they matched the inclusion criteria, and all agreed to do so. Thus, all participants were involved in ITE and were well placed to comment on nature and impact of the interdependent relationships that they had developed with other individuals and groups over the duration of their one-year programme. A convenience sampling method (Roberts, 2009) was also used. Participants were studying at one institution in the north-west of England and were recruited, to some degree, for their proximity and availability.

The study used questionnaires and one-to-one interviews with ATs to gather data on the nature and impact of the interdependent relationships that they had developed with others. Questionnaires were completed twice: part way through and towards the end of the one-year 
postgraduate programme. The questionnaires asked ATs to identify who was involved in their learning network during the one-year programme and how much impact they had over their development as teachers. To this end, ATs were given a blank network map that enabled them to locate all those who had influenced their development on a scale of 10 (most influential) to 1 (least influential). This approach was simple and easy to administer (Denscombe, 2017) and produced a basic diagrammatical representation of a figuration.

The initial data gained from the questionnaires provided a useful starting point as they identified the networks in which ATs worked and learned, but the approach was limited as ATs were not able to clarify or explain their responses in any detail (Denscombe, 2017). As such, semi-structured interviews were conducted with all ATs at the end of the one-year programme so that they could elaborate on their initial responses and provide greater insights. The interviews with the 35 participants were on average 42 minutes in duration and began with questions that asked them to reflect on the nature of their learning networks. The use of semistructured interviews is thought to be particularly well suited to the figurational approach because of the depth of data they can provide (Bloyce, 2004). Semi-structured interviews allow the researcher a deeper level of insight into respondents' thoughts and experiences as they enable the interviewer to not only capture the views of the respondent, but also to understand the context, relationships and constraints that influence their everyday life (Denzin \& Lincoln, 2011). The standardised nature of most of the questions in a semi-structured interview also allows for relatively easy comparison between the data gathered from different respondents at different sites (Bryman, 2012). But while the interviewer had a standardised interview schedule, there was also some latitude to ask follow-up questions, thereby allowing the interviewee to elaborate and explain their thoughts and experiences in greater depth. By adopting this technique, the researchers had the flexibility to enter into a dialogue with the ATs, to clarify more complex issues and elicit data that may otherwise have remained uncovered (Gratton \& Jones, 2010).

While probing for additional answers may have provided a richer level of information, this aspect of semi-structured interviews does create a problem of comparing non-standard responses. As such, analysis of data is more complex when using semi-structured interviews than when respondents are restricted to a more formal and structured approach (Bryman, 2012). That said, figurationalists would always argue that any difficulties are outweighed by the richness of data and insights provided by semi-structured interviews (Bloyce, 2004). 
The interviews with each AT were audio recorded and transcribed and organised alongside the initial data from the learning networks questionnaires. A process of content analysis was then used to systematically review the text and identify patterns in the data. Content analysis is thought to be a clear and repeatable approach to analysing written communication (Gratton and Jones, 2010). It begins with the identification of key words or phrases, which are then assigned labels and arranged in categories. The coding of key words in this way was used to organise the data, guide further analysis of the text and develop a more adequate understanding of the ATs' learning networks (Denscombe, 2017). Content analysis is a commonly used systematic approach that is adopted to quantify the content of a text. It is a process that reveals the values and patterns contained within a transcript and is considered to be an effective approach for analysing data, classifying themes and identifying findings (Gratton and Jones, 2010). The following section examines the findings that emerged from the data, with individual ATs identified by a number (AT1-AT35) reflecting their place in the sequence of interviews.

\section{Discussion of Findings: A Figurational Analysis}

All ATs mapped their learning networks on two separate occasions during the training year. The first occurred at the halfway point, while the second occurred at the end of the year. On average, ATs initially included 9.7 people in their network, with this number rising to 10.4 by the end of the programme. This reflected the dynamic nature of social relations (Van Krieken, 1998) as the individuals involved in the ATs' networks changed over time, as did the strength and nature of the bonds that held them together. Table 1 represents the perceptions of the 35 ATs about who influenced their learning during the training year.

Table 1. Physical Education Associate Teachers' Learning Networks

\begin{tabular}{|l|c|c|}
\hline Description of Person/Role & $\begin{array}{c}\text { Frequency of Inclusion in } \\
\text { ATs' Networks } \\
\text { (Expressed as a } \\
\text { Percentage) }\end{array}$ & Average Influence \\
\hline PE Mentor Placement 2 & 100 & 8.6 \\
\hline PE University Tutor & 91 & 7.4 \\
\hline PE Mentor Placement 1 & 86 & 7.0 \\
\hline Professional Mentor Placement 2 & 71 & 5.2 \\
\hline PE Teacher (Female) Placement 1 & 63 & 6.3 \\
\hline PE Teacher (Male) Placement 2 & 63 & 6.1 \\
\hline ATs from PE & 59 & 5.8 \\
\hline
\end{tabular}




\begin{tabular}{|l|c|c|}
\hline PE Teacher (Male) Placement 1 & 57 & 6.0 \\
\hline ATs from Another Subject & 54 & 4.1 \\
\hline Masters Tutor & 53 & 3.9 \\
\hline PE Teacher (Female) Placement 2 & 50 & 6.5 \\
\hline Professional Mentor Placement 1 & 50 & 4.8 \\
\hline Friend & 37 & 3.6 \\
\hline Sports Team Coach & 29 & 3.2 \\
\hline PE Head of Department Placement 2 & 26 & 7.0 \\
\hline Form Teacher & 26 & 4.5 \\
\hline Teacher (Other Subject) & 24 & 3.5 \\
\hline Deputy Head & 20 & 5.2 \\
\hline Parent & 19 & 5.0 \\
\hline Primary Placement Teacher & 14 & 6.0 \\
\hline Newly Qualified PE Teacher & 11 & 6.3 \\
\hline Girlfriend/Boyfriend & 9 & 6.8 \\
\hline PE Head of Department Placement 1 & 9 & 6.0 \\
\hline Former PE teacher & 9 & 2.5 \\
\hline Headteacher & 6 & 3.3 \\
\hline Pupils & 6 & 2.8 \\
\hline Brother & 3 & 4.0 \\
\hline Teaching Assistant & 3 & 4.0 \\
\hline Friend (Teacher) & 3 & 1.0 \\
\hline
\end{tabular}

The people identified by the ATs were categorised into 29 different roles in all, and although they were represented simplistically, this raised the challenge of understanding the different mentoring roles played by individuals within complex figurations (Brondyk and Searby, 2013; Van Krieken, 1998). The learning networks included a wide range of less frequently noted individuals, such as friends and family members, sports team coaches and former teachers who seemingly provided support for the ATs or offered specific insights and ideas. One AT noted the role of his father: 'He's disabled, and he teaches deaf children. Being in that SEN environment with him and spending every day with him has made my practice better. I'm always very aware of making everything accessible to young kids' (AT4). The formative influence of family members was recognised by Green (2003), as early experiences are thought to establish a deeply rooted habitus. In this case, the father remained a constant reminder of the ATs' habitus and influenced his teaching approach accordingly. That said, while ATs included influential people who were previously known to them, the focus of this study was the figurations of ATs during their training year. During this period, the most commonly identified people within the learning networks were those who worked in either an official or unofficial capacity alongside the ATs in their placement schools and at the university. As such, the 
influence of the subject and professional mentors, the university tutor and other ATs, and finally other PE teachers, is now discussed in more detail.

\section{Mentors}

The subject mentors were more experienced PE teachers who had agreed to undergo training and work in a formal capacity with ATs to help develop their subject knowledge and teaching skills. Not surprisingly, they were identified as the people who had the greatest impact on the ATs' learning. One AT noted, 'My subject mentor was at the centre, he was the biggest influence, the one that shaped my approach to teaching' (AT3). ATs will work with a range of teachers in the PE department of their placement schools, with some individual teachers identified as being more important than others. That said, for the ATs, the most influential member of the department was the one who had most power: the mentor. Elias (1978) believed that power is an inevitable characteristic of human relationships as some individuals within figurations inevitably have greater proportions of the resources that are needed by others. In this instance, most ATs initially attributed the degree of their mentor's influence to their proximity and support: 'I spend most of my time with him, watching him teach, getting guidance, feedback and advice' (AT25). Moreover, ATs referred to the role that mentors played in their assessment: 'We have to have that weekly observation and meeting with our mentor to assess my progress and fill out the forms' (AT14). The mentor is the individual who guided the AT's learning and is also the person who assessed progress and decided whether the AT had passed the programme to become a qualified teacher. As such, ATs relied on mentors, who were in a relatively powerful position as they possessed a greater proportion of the resources that ATs needed to successfully complete their ITE programme.

The balance of power that existed between the AT and the mentor could distort the connection that exists between them: 'It's a forced relationship. You have to build a relationship with your mentor, they're your mentor at the end of the day. Whereas with anyone else it's a bit more natural' (AT16). The relatively powerful position of the mentor can also lead to an unintended outcome, what Hobson and Malderez (2013) termed judgementoring, where ATs were apprehensive at the thought of being assessed. One AT explained, 'You really want to impress your mentor because they're the one filling out your form, they're the one who will grade you at the end' (AT27). Elias (1978) wanted to counter any simplistic interpretation of the relationship between human action and its outcomes (Van Krieken, 1998). He believed that 
human interaction within figurations has both intended consequences and also unplanned outcomes that are not anticipated or controlled. Within the context of ITE, the mentor has a dual role of guiding and assessing the ATs' progress. It would seem that the latter, the judging and grading of an AT's teaching, often unintentionally undermined and impeded their progress: 'My mentor's great, but I do get a bit anxious in an assessment lesson. I think I do better when I'm teaching the lessons of other teachers and the pressure's off a bit' (AT2).

The ATs completed two school placements over the training year and subsequently had two different subject mentors. The ATs valued working with both, but the mentor at the second placement school was shown to have had more impact on the development of the ATs, having an average rating for their influence of 8.6 out of 10 , by comparison with 7.0 for the placement one mentor. This reflected the dynamic nature of relations within a figuration, as social interdependencies are thought to change over time (Van Krieken, 1998). At the beginning of placement one, the ATs had less understanding of the school context and were more reliant on the mentor: 'At the start you're a bit of a lost lamb, just following your mentor round, not really knowing what to do' (AT2). Over time, however, ATs developed their confidence and were able to lead more lessons and extracurricular clubs: 'By placement two I really felt like I was making a valuable contribution, I wasn't just there as a spare part' (AT31). In some cases, the relationship progressed to a point where the mentor sought the assistance of the AT: 'He's asked can you come and observe me teaching this because he knows I'm a rugby specialist and wants to know if there's a better way of doing it. It's nice, it makes you feel more valued' (AT22). Elias (1978) believed that when two or more people bond, the influential relationship that exists between them is fostered by their mutual dependency on the other(s) to provide a resource. Elias also used the term 'power balance' to convey his conception of power as being a fluid entity rather than something that is set in a permanent state (Murphy et al., 2000). In this instance, the balance of power that existed between ATs and mentors changed over the duration of the year. ATs developed expertise and had more resources to offer mentors, which strengthened the mutually interdependent bonds that existed between them (Van Krieken, 1998).

The ATs also worked with a professional mentor at both placement schools. The professional mentor was typically a senior member of staff who had overall responsibility for teacher education at the school. They liaised with the university to manage placements and also contributed to the general training and assessment of all ATs who were working in different 
specialist subjects at the school. Professional mentors had comparatively little impact on ATs' development as teachers, being rated 5.0 out of 10 for their overall influence. That said, the ATs' perception of the professional mentors followed the same pattern as the subject mentors, with the professional mentor at the second school being considered to have had more influence than the one at the first placement school: 'She kind of left us to it, I think I had like two conversations with her on placement one, but that's completely contrasted with placement two where my professional mentor is really involved and helpful, especially with jobs' (AT7). During placement two, the nature and strength of the bonds that existed between the AT and the professional mentor changed (Van Krieken, 1998) as ATs were applying for jobs and working towards the final review and grading of their teaching. At this time, professional mentors inevitably became more influential as the relationship that existed between them was fostered by the ATs' reliance on them to support job applications and moderate the final assessment.

\section{University tutor}

The university tutor was the second most commonly identified person within the ATs' learning networks and was also the second most influential, at an average of 7.4 out of 10 . The tutor coordinated school placements and taught the ATs during 20 university-based subject days that take place over the training year. The tutor was most commonly valued for his role in developing subject and pedagogical knowledge: 'The PGCE lecturer has been amazing, giving us all the sports, all the ideas on how to structure the lessons. Especially gymnastics, that's not my specialism, but the way it's been taught has encouraged me to feel much more confident' (AT15). Moreover, the ideas provided by the tutor were especially valued for their currency in the school environment: 'Sharing different things, doing all the different sports, I've used it within schools, it's translated across. We did that pacing lesson didn't we? I've used that and it really worked' (AT17).

ATs work in a PE community that is particularly resistant to change (Green, 2006). The teachers who had taught the ATs at school, the university tutor and the teachers on placement ostensibly shared complementary beliefs and characteristics. This would be described by Elias (1991) as social habitus, where similar features are shared across a community. ATs readily accepted the pedagogical ideas provided by the tutor, partly because of the power balance that existed between them but also because the ideas were consistent with the approaches they 
experienced in school. Indeed, it is likely that if the tutor's ideas were dissimilar, then their influence and power would diminish as they would play a less relevant role in the figuration.

The tutor was not the only source of subject and pedagogical knowledge in these sessions, as the ATs were also encouraged to contribute and share. Indeed, the ATs commonly included their peers within their learning networks, albeit at a lower level of influence, being rated at 5.8 out of 10. Other ATs were valued for their empathy: 'We were all going through the same thing, so their support helped enormously' (AT24). They were also valued as a lesson planning resource: 'Everyone can chip in their ideas as everyone specialises in different things' (AT23). In this way, the university sessions provided a valued opportunity for the transfer of learning: 'I think those days are really, really worthwhile because it's a bit more of a relaxed way to pick up ideas and speak to people about their experiences' (AT4). The ideas provided by their peers added to ATs' subject knowledge and were readily accepted as they were broadly consistent with their social habitus (Elias, 1991). Elias would argue that the norms and values of the PE community have been socially constructed and passed on by earlier human relationships (Murphy et al., 2000). As such, the ideas that ATs experienced in university sessions, be they from the tutor or from other ATs, fitted with the standard way of conceiving PE and thus were readily accepted. In this way, new experiences within the PE community were more likely to reinforce the habitus of the ATs than challenge their established beliefs and practices.

\section{Physical education teachers}

The other teachers in the PE departments that the ATs worked in were the third most influential group within their learning networks, being rated 6.2 out of 10 . The departmental team was made up of a small number of PE teachers who shared responsibility for teaching the subject and leading extracurricular school sport.

The culture and norms of the departmental figurations that the ATs were part of were broadly described as being supportive and aspirational: 'They just want me to do well and expect a lot from me. They want me to be the best I can be, and I think that's had the biggest impact' (AT18). Moreover, ATs recognised the benefits of working in a cohesive department: 'We have a meeting every week and everyone is willing to share best practice. They're all pulling in the same way and they're happy to share, so it's been easier for me to settle in and easier to make progress' (AT14). The balance of power within a department often lies with more 
experienced and influential teachers who establish the social habitus of that particular community (Elias, 1991). As new and inexperienced members of the department, ATs were susceptible to the influences of the immediate figuration in which they worked and this had a positive or a more detrimental effect on their teaching: 'I'd say it's made me lazier, because there isn't an expectation to teach in a good way and I find that difficult. It's made me lazy, because if you can do this job and not try, then why am I bothering to get better?' (AT26). ATs were exposed to PE departments for a comparatively short period of time, but nonetheless they did begin to influence their habitus and affect their unplanned behaviour (Van Krieken, 1998). Moreover, a small number of ATs had experienced situations where they were in obvious conflict with the established norms of the department. ATs were, for example, not always able to teach clearly structured sequences of lessons with the same class: 'It's quite disorganised. I've had lessons where I've not taught my class, I've got all three girls' groups at the last minute, and they say ... off you go. And it's happened a lot' (AT8). This disruption restricted the opportunity for the AT to teach in any meaningful way. It limited learning and made it harder for the AT to gather the evidence needed to demonstrate competence and pass the programme. ATs work in complex networks where pressures are exerted in different ways and directions and work together to constrain or enable their behaviour (Green, 2002). In this instance, ATs were influenced by their inclusion in a wider figuration with policy makers and organisations who dictated how ITE was conducted. The relationships within these figurations might not have been face-to-face, but they nonetheless determined the expectations of the placement (Green, 2003). When the organisation of teaching within the PE department is not consistent with the requirements of ITE, the pressures exerted on the AT are not straightforward and can constrain their behaviour. As such, ATs become reliant on their mentor, who is in a more powerful position within the figuration, to act on their behalf and secure teaching opportunities that are more conducive for professional learning.

Mentors were charged with managing the learning of the AT within the department. That said, a quarter of the ATs believed that a particular PE teacher had more or the same impact on their professional development and in effect became an 'unofficial mentor'. This revealed the complex nature of mentoring relationships and the alternate forms that they could take within different educational figurations (Brondyk and Searby, 2013). As is shown below, ATs typically developed interdependent mentoring relationships with seemingly more effective teachers, younger members of the department and those who were perceived to have a similar teaching approach. 
The relationship that developed between the ATs and PE teachers was often initially attributed to the organisation of the placement: 'I'm timetabled with her for most of my lessons, so it's just spending time together' (AT19). In most instances, though, the relationships that developed were ascribed to similarities in personalities and approaches to teaching: 'We had a natural rapport. We had a similar attitude around the kids. We got on more because we taught the same' (AT11). The habitus of human beings is rooted in the relationships that they form within figurations, and in this instance, ATs were seemingly drawn to professional relationships where a shared social habitus (Elias, 1991) mutually reinforced existing beliefs: 'If you have a similar approach about how outcomes should be achieved, you're going to see things in the same way and maybe those people naturally come together' (AT13). It was also acknowledged that it was difficult for ATs to build relationships with some members of the department: 'Some of the PE teachers there I wouldn't go to because they're just too hard to talk to. They might be senior leaders and know their stuff, but I just haven't got the same relationship' (AT8). Conversely, one AT noted how she had developed a closer relationship with a newly qualified teacher who was 'heavily involved in the netball after school and my subject mentor doesn't do a lot. I've started leading the netball and I think because I've supported her as a new teacher and she's supported me, our friendship has grown' (AT27). When two or more people bond within a figuration, their relationship is fostered by their mutual dependency on the other(s) to provide a resource (Elias, 1978). For ATs, it is easier to establish a bond and gain influence when the balance of power and distribution of resources are more equal. Thus, some ATs noted how they developed a relationship with younger and more inexperienced teachers who themselves had recently completed their ITE programme. Finally, ATs recognised the value of other respected members of department who may not have had a direct responsibility for supporting their progress but did nonetheless act as mentors to provide support for their development as teachers. One AT noted, 'The head of PE in our department has been a massive support just always asking you different questions or giving you another idea. He's a really good teacher so he's been a big influence' (AT34). Effective teachers were more prominent in the figurations of ATs. The resources that made them successful also gave them influence and ATs often looked to them for advice.

ATs also looked to emulate the effective teaching approaches of their mentors, but while there were similarities in the ways that ATs learned from other teachers, there were differences, too: 'A lot of it comes down to the informality of having a chat with another teacher as opposed to 
that weekly meeting with your mentor where you are filling out targets. The relationship is just slightly different really. Not as much pressure' (AT30). Another AT similarly explained the differences between working with the teacher and the mentor: 'With the teacher you can be that much more open, still giving you lesson feedback, but maybe you don't take things to heart as much and that helps you do better' (AT27). The strength and nature of the bonds that hold individuals together in a figuration vary (Van Krieken, 1998). Mentors have a clearly defined role to play in nurturing and assessing ATs as they progress towards qualified teacher status. The mentor can provide more informal feedback, but in their official capacity, they must also complete regular formal lesson observations. This can lead to an unintended outcome of 'judgementoring' where ATs' teaching is impeded by the pressure of assessment (Hobson and Malderez, 2013). In contrast, teachers do not have such a relatively powerful position within the figuration. Teachers are not involved in the formal assessment of ATs and can build nonevaluative social relationships that support their development and promote their acceptance as part of the department.

\section{Conclusion}

This paper examined ATs' learning networks to develop a more adequate understanding of how they are influenced by those they work alongside during their one-year postgraduate ITE programme. The analysis inevitably focused on the ATs' interdependent relationships with their designated mentors, but also considered the influence of other individuals, particularly the university tutor, other PE teachers and, to a lesser extent, other PE ATs.

The mentor was the most influential person in the ATs' figurations as they were expected to guide the ATs' learning and make a judgement about their performance. These expectations could be contradictory at times as the necessity of assessing the ATs' teaching performance caused anxiety that could unintentionally impeded their progress. This finding led to questions about the organisation and assessment of ITE, particularly as some ATs felt empowered by the non-evaluative relationship that they had developed with other teachers in the department. Reducing the number of formal observations completed by the mentor, or even entirely removing the expectation for the subject mentor to be involved in the assessment process, altered power relationships and potentially reduced the ATs' anxiety. 
The university tutor had a positive impact on developing relevant subject and pedagogical knowledge but may have also unintentionally prepared ATs to accept rather than challenge existing school practice. All of those who were identified as being an influential part of the ATs' learning networks were part of the same PE community, a subject-based figuration where interdependent people's thoughts and behaviours were constrained by their social habitus (Green, 2006). As such, PE teaching has remained relatively stable despite changes in curriculum policy and the inclusion of more innovative practice in many training programmes. The university sessions were a comparatively short intervention as most of the year was spent in extended school placements where established mentors and teachers were in a relatively powerful position to influence the teaching of ATs who wanted to be accepted and valued (Keay, 2009). That is not to say that members of school PE departments conspire to deliberately suppress innovation and change, rather that their unplanned behaviour may unintentionally reinforce existing approaches to teaching $\mathrm{PE}$ as it is also circumscribed by their interdependence with other teachers within broader social networks. Thus, it seems that, if ATs are expected to explore innovative approaches to teaching and to share their learning with others, tutors need to collaborate with mentors and teachers to develop awareness of their oftenunplanned influence.

Finally, other PE teachers were the third most influential group within the ATs' learning networks. ATs recognised the value of working in a cohesive department where the social habitus allowed teachers to share their expertise and work collaboratively with others. As such, ITE providers should consider which PE departments are used as placements for ATs and should also focus part of their mentor training on other PE teachers who will influence the ATs as they work alongside them daily. Mentor training based in the PE department would recognise the contexts of the mentor, teachers and the ATs. It would raise teachers' awareness of their role and would seemingly sensitise them to the value of their collaborative relationships. Mentor training organised in this way would help legitimise the PE department as a place for sharing and creating ideas and seemingly promote the active involvement of ATs.

\section{References}

Alfrey, L. and Gard, M. (2019), "Figuring out the prevalence of fitness testing in physical education: A figurational analysis", European Physical Education Review, Vol. 25 No. 1, pp. 187-202. 
Bloyce, D. (2004), "Research is a messy process: A case-study of a figurational sociological approach to conventional issues in social science research methods", The Graduate Journal of Social Science, Vol. 1 No. 1, pp. 144-166.

Bokeno, R. and Gantt, V. (2000), "Dialogic mentoring: core relationships for organizational learning”, Management Communication Quarterly, Vol. 14 No. 2, pp. 237-270.

Brondyk, S. and Searby, L. (2013), "Best practices in mentoring: complexities and possibilities", International Journal of Mentoring and Coaching in Education, Vol. 2 No. 3, pp.189-203.

Bryman, A. (2012), Social research methods: fourth edition, Oxford University Press, Oxford, United Kingdom.

Cassidy, T., Jones, R. and Potrac, P. (2004), Understanding sports coaching: The social, cultural and pedagogical foundations of coaching practice, Routledge, Abingdon, United Kingdom.

Denzin, N. and Lincoln, Y. (2011), The SAGE handbook of qualitative research, Sage, London, United Kingdom.

Denscombe, M. (2017), The good research guide for small scale social research projects: sixth edition, Open University Pres, London, United Kingdom.

Dunning, E. (2002), "Figurational Contributions to the Sociological Study of Sport", in Maguire, J. and Young, K. (Eds.), Theory, Sport and Society, Elsevier Science, Oxford, United Kingdom, pp. 211-38.

Dunning, E. and Hughes, J. (2013), Norbert Elias and modern sociology: Knowledge, interdependence, power, process, Bloomsbury Academic, London, United Kingdom.

Elias, N. (1978), What is Sociology?, Hutchinson, London, United Kingdom.

Elias, N. (1987a), "The Retreat of Sociologists into the Present", Theory, Culture \& Society, Vol. 4 No. 2, pp. 223-247.

Elias, N. (1987), Involvement and Detachment, Basil Blackwell, Oxford, United Kingdom.

Elias, N. (1988), "Violence and civilization: The state monopoly of physical violence and its infringement", in Keane, J. (Ed.), Civil society and the state, Verso, London, United Kingdom, pp. 177-198.

Elias, N. (1991 [1987]), The Society of Individuals, Basil Blackwell, Oxford, United Kingdom.

Elias, N. (1994[1939]), The Civilizing Process, Basil Blackwell, Oxford, United Kingdom.

Fletcher, J. (2013), Violence and civilization: An introduction to the work of Norbert Elias, Polity Press, Cambridge, United Kingdom. 
Gordon, E.J. (2017), "Exploring the dyad: the relationship establishment between a novice physical education teacher and his mentor", Mentoring and Tutoring: Partnership in Learning, Vol. 25 No. 1, pp. 27-41.

Gratton, C. and Jones, I. (2010), Research Methods for Sports Studies, Routledge, London, United Kingdom.

Green, K. (2000), “Exploring the everyday 'philosophies' of physical education teachers from a sociological perspective", Sport, Education and Society, Vol. 5 No. 2, pp. 109129.

Green, K. (2002), "Physical education teachers in their figurations: A sociological analysis of everyday "philosophies"”, Sport, Education and Society, Vol. 7 No. 1, pp. 65-83.

Green, K. (2003), Physical education teachers on physical education. Chester Academic Press, Chester, United Kingdom.

Green, K. (2006), "Physical Education and Figurational Sociology: An Appreciation of the Work of Eric Dunning", Sport in Society, Vol. 9 No. 4, pp. 650-65.

Hobson, A.J. (2016), "Judgementoring and how to avert it: introducing ONSIDE Mentoring for beginning teachers", International Journal of Mentoring and Coaching in Education, Vol. 5 No.2, pp. 87-110.

Hobson, A.J. and Malderez, A. (2013), "Judgementoring and other threats to realizing the potential of school-based mentoring in teacher education", International Journal of Mentoring and Coaching in Education, Vol. 2 No. 2, pp. 89-108.

Jones, L., Tones, S. and Foulkes, G. (2018), "Mentoring Associate Teachers in Initial Teacher Education: The Value of Dialogic Feedback", International Journal of Mentoring and Coaching in Education, Vol. 7 No. 2, pp. 127-138.

Jones, L., Tones, S. and Foulkes, G. (2019), "Exploring Learning Conversations between Mentors and Associate Teachers in Initial Teacher Education", International Journal of Mentoring and Coaching in Education, Vol. 8 No. 2, pp. 120-133.

Keay, J. (2009), “Being influenced or being an influence: New teachers' induction experiences”, European Physical Education Review, Vol. 15 No. 2, pp. 225-247.

Lofthouse, R. (2017), “Improving Mentoring Practices through Collaborative Conversations”, available at: https://www.schooleducationgateway.eu/en/pub/viewpoints/experts/improvingmentoring-practices-.htm (accessed 1 July 2019).

Lofthouse, R. and Wright, D. (2012), "Teacher education lesson observation as boundary crossing", International Journal of Mentoring and Coaching in Education, Vol. 1 No. 2, pp. 89-103.

Mennell, S. (1998), Norbert Elias: An introduction. University College Dublin Press, Dublin, Ireland. 
Murphy, P., Sheard, K. and Waddington, I. (2000), "Figurational Sociology and its Application to Sport", in Coakley, J. and Dunning, E. (Eds.), Handbook of sports studies, Sage, London, United Kingdom, pp. 92-106.

Nahmad-Williams, L. and Taylor, C.A. (2015), "Experimenting with dialogic mentoring: a new model", International Journal of Mentoring and Coaching in Education, Vol. 4 No. 3, pp. 184-199.

Roberts, K. (2009), Key concepts in sociology, Palgrave Macmillan, London, United Kingdom.

Rojek, C. (1992), “The Field of Play in Sport and Leisure Studies”, in Dunning, E. and Rojek, C. (Eds.), Sport and Leisure in the Civilizing Process, Macmillan, London, United Kingdom, pp. 1-35.

Van Krieken, R. (1998), Norbert Elias. Routledge, New York, NY.

Wang, J. and Odell, S.J. (2002), "Mentored Learning to Teach According to Standards-Based Reform: A Critical Review”, Review of Educational Research, Vol. 72 No. 3, pp. 481-546. 